\title{
Towards a pedagogy of accessibility: The need for critical learning spaces in media accessibility education and training
}

\author{
Gian Maria Greco \\ TransMedia Catalonia, Autonomous University of Barcelona, Spain \\ GALMA, University of Vigo, Spain \\ gianmaria.greco@poiesis.it \\ https://orcid.org/0000-0002-8714-6349
}

\begin{abstract}
Until now, the debate on education and training in accessibility has largely ignored the core competences of the accessibility expert, as it has tended to focus exclusively on context- and field-related skills. Looking at the case of media accessibility through the critical lens of accessibility studies, the article calls for the development of a theoretical reflection on education and training. Such reflection could then solidly support extensive investigation of the specific skills of accessibility researchers, professionals and policy-makers, frame analyses of current programmes, and strengthen proposals for new curricula and professional profiles. The article contributes to such a reflection by advancing and discussing the inclusion of critical learning spaces within vocation- and research-oriented courses. Using the critical lens of accessibility studies, the article also investigates whether education and training in audiovisual translation and media accessibility have been mostly dominated by some discriminatory normative frameworks, such as the medical model of disability, and how this is influenced by and in turn influences practices. The article suggests that this problem requires a (re)design of education (and practices) using the tools that constitute the critical apparatus of accessibility studies, such as the human variation paradigm, the social model of accessibility, the universalist account of access, the poietic model of agency, and proactive and user-centred approaches. Ultimately, the article outlines the very first traits of a pedagogy of accessibility, that is, a systematic approach to the practice(s) of teaching and learning accessibility.
\end{abstract}

Keywords: accessibility, accessibility expert, accessibility studies, audiovisual translation, critical learning spaces, critical theory, curriculum design, guidelines, implicit bias, media accessibility, medical model of disability, pedagogy of accessibility, practice, proactive approaches, social model of accessibility, social model of disability, stigmatization, universalist account, user-centred approaches

\section{Introduction}

What should we teach? How should we teach it? And, ultimately, why should we teach it? Questions concerning education are among the oldest and most persistent issues in human thought, for they go to the core of some of humankind's most distinctive activities: knowledge 
Greco, G. M. (2019). Towards a pedagogy of accessibility: The need for critical learning spaces in media accessibility education and training. Linguistica Antverpiensia, New Series: Themes in Translation Studies, 18, 23-46.

production, organization, and transmission. Topics related to education have been pivotal in theoretical, social and ethical debates, for different theories about social relations, social phenomena, morality and, ultimately, what it means to be human infuse different theories of education, and vice versa. We teach students the past and train them about the present in order to prepare them for the future. We shape our structures of education based on the choice of some specific interpretative lens through which we read the past and the present as well as the choice of some specific forecast of how our future will or ought to be.

Education is one of the key grounds where disciplines and research fields have tested their epistemological status. In the introduction to a seminal collection of essays on the didactics of audiovisual translation (AVT), Díaz-Cintas (2008) argued for the need for more consistent attention to be paid to pedagogical issues in the field of AVT, both from a theoretical and from a practical perspective, precisely as a way of furthering the position of AVT as a research field. Looking at the vast literature on AVT education and training produced since that publication, one can say that his argument has been embraced by many. However, the situation of education and training in accessibility, including media accessibility (MA), has proved to be quite different.

Over the past few decades, many fields have undergone a series of profound changes as a consequence of the ontological, epistemological, and methodological shifts produced by accessibility. In a nutshell: once it entered those fields, accessibility often began to produce specific sub-domains within them, which resulted in a gradual movement outside the exclusive sphere of influence of their respective fields. This steady convergence ultimately led to the birth of Accessibility Studies (AS) as an interdisciplinary research field in its own right (Greco, 2018). MA is one of those areas that have both experienced and contributed to the process of formation of AS. The increasing role of accessibility as a pivotal concept in AVT, the new position acquired by MA in relation to AVT, and the emergence of AS all call for evergreater engagement in both research on and the implementation of education and training. This is an engagement that - similarly to Díaz-Cintas's (2008) aforementioned argument for AVT - should deal with both practical and theoretical issues in accessibility education. It is an engagement that should be directed towards the specific pedagogical issues related to accessibility. An engagement that should analyse those courses in which accessibility is (or should be) a curricular topic. An engagement that should support a careful examination of the rules we teach in those curricula and promote an analysis of current MA practices.

However, to date, the vast majority of the work produced on MA education and training has focused mainly on providing and discussing lists of the skills and competences of some specific vocational profile or on offering proposals for particular training courses. The theoretical perspective is what is most lacking, which is a condition shared by research on and the implementation of education and training in other fields and sub-domains that have been influenced by accessibility.

My main goal in this article is to highlight the need for theoretical reflection upon the pedagogical issues of accessibility by applying the critical apparatus of AS to the cases of MA and AVT. It is neither a call for the priority of theory over practice in curricula nor a claim of the subsidiary importance of vocational skills as compared to research ones. Rather, it is a plea 
Greco, G. M. (2019). Towards a pedagogy of accessibility: The need for critical learning spaces in media accessibility education and training. Linguistica Antverpiensia, New Series: Themes in Translation Studies, 18, 23-46.

for the development of systematic theoretical reflection on accessibility education and training. Such reflection could then solidly support extensive investigation on the distinctive skills of professionals and researchers, frame analyses of current courses, and strengthen proposals of new curricula and professional profiles. The pedagogical question inherently connects with one of the most crucial issues in accessibility, namely, quality. The methods researchers use to investigate quality and the related theories they develop, the parameters and the metrics policy-makers adopt in public policies to define and evaluate quality thresholds, and the way practitioners make use of research results and follow guidelines are tightly interwoven into the mindset that education and training have rooted in those researchers, policy-makers, and practitioners.

In this article I contribute to such a reflection by advancing the following tenets: $(a)$ that accessibility calls for the inclusion in vocation- and research-oriented courses of what I refer to as critical learning spaces, where students can acquire and hone a critical attitude required by the theoretical and social implications of accessibility; and $(b)$ that, more generally, the critical apparatus of AS can be used as a tool for analysing education and training curricula. Through the critical lens of AS, I then investigate whether education and training programmes in MA have both been influenced by and continue to propagate some discriminatory normative assumptions, such as the medical model of disability, in (some) MA practices. And I conclude that $(c)$ this problem can be successfully dealt with by using the critical apparatus of AS to (re)design both AVT and MA education and AVT and MA practices. As such, with this article, I ultimately attempt to sketch the initial lines of a pedagogy of accessibility, a systematic approach to the practice(s) of teaching and learning accessibility.

More specifically, in section two I provide some clarification which will serve to better identify the framework within which this article is positioned. In section three, I analyse the normative frameworks connected to the different accounts of MA, with a focus on the medical model and the social model of disability. In section four, I consider the critical nature of AS, discuss the influence of the medical model of disability on MA practices, and then introduce the idea of critical learning spaces. In section five, I delve further into the structure, function and content of such spaces. In section six, I consider two possible objections to the implementation of critical learning spaces and to curricular (re)design based on the critical apparatus of AS. Finally, in section seven, I outline the general traits of a new model of MA education and practice, and provide some concluding thoughts on the wider importance of critical learning spaces and the critical lens of AS.

\section{Some preliminary clarifications}

Before moving on to the next sections, some clarifications are in order so as to better delineate both the framework within which this article moves and what the article is not about. In education and curriculum design, clearly defined and widely accepted terminology does not exist for certain concepts. Even the glossary included in the ECTS Users' Guide presents some confusing passages (European Commission, 2015). In the following pages, I: (a) use "programmes" to indicate self-contained vocational and academic courses, as further specified a few lines below; $(b)$ consider that each course is organized into one or more modules; and $(c)$ consider a module as organized into one or more units, which may be 
Greco, G. M. (2019). Towards a pedagogy of accessibility: The need for critical learning spaces in media accessibility education and training. Linguistica Antverpiensia, New Series: Themes in Translation Studies, 18, 23-46.

grouped into sub-modules. ${ }^{1}$ More specifically, I use academic education or professional training (ET), where or is an inclusive disjunction, in the following way: academic education refers mainly to research-oriented graduate and post-graduate courses - such as master's, post-graduate diplomas, and doctoral programmes - usually but not exclusively offered by higher-education institutions; professional training refers mostly to vocationally oriented courses - such as master's, diplomas, and short courses - offered by either higher-education institutions or other actors such as companies and organizations. While in reality such a distinction is much less sharp, its role here is simply to preclude the need for further details of analysis that do not have an impact on my general argument.

Referring to ET in this sense also implies that undergraduate courses are not included in the analysis I carry out in this article. The main reason for this is that undergraduate curricula are mostly anchored in traditional disciplines (e.g., sociology, fine arts, physics) or wider research fields (e.g., neuroscience), whereas professional training and postgraduate education often focus on an area or a topic in those disciplines and fields, some interdisciplinary area or topic, or some specific vocational profile. Expanding the analysis to the undergraduate level would mean straying towards a different horizon, for instance, dealing with the long-standing debate on disciplines as organizing and organized structures for knowledge production and transmission. These are issues of great relevance without a doubt, but they are beyond the scope of these pages.

There are currently no ET programmes in MA that are based exclusively and entirely on an ASoriented interpretation of MA. At this time, there is not, for instance, a Master of Arts in Media Accessibility or a training course in Media Accessibility grounded on a systematic and integrated account of MA as an area of AS. ${ }^{2}$ In accordance with the new position of MA, an argument could (or even should) be made for such specific ET programmes: courses that are able fully to express and embrace the new position of MA as an area in the interdisciplinary field of AS. Such an argument should, for example, analyse and justify the distinctive features of ET courses in MA. It should also compare them with other programmes where accessibility and MA play an important role but are presented as only one piece of a more traditional mosaic - for example, certain ET courses in AVT or Human-Computer Interaction. So far, accessibility and MA have nearly always been dealt with as part of the latter type of ET programmes, as highlighted by the case of many academic and vocational courses in AVT. For this reason, my interest in this article lies precisely in dealing with accessibility in these types of course, not in arguing in favour of some new AS-based course in MA.

A final clarification as to the scope and contribution of this article is in order. I seek to draw attention to the need for a debate on the theoretical issues, and the pedagogical issues from a theoretical perspective, related to the research, development, and implementation of ET programmes in accessibility by focusing on the case of MA and AVT. I do so by embracing a stance similar to that adopted by Pym $(1991,2003)$ in addressing the problems of ET in Translation Studies. That is, in the ensuing pages, I provide neither a list of the skills and competences of the MA expert nor the layout and the curriculum of an ET programme in MA. Rather, my aim is to initiate a debate on "the general theoretical and pedagogical problem involved" (Pym, 2003, p. 482). It also means that, as in Pym's case, the article itself is mainly theoretical, not practical. It contributes to the debate by advancing the idea of critical learning 
Greco, G. M. (2019). Towards a pedagogy of accessibility: The need for critical learning spaces in media accessibility education and training. Linguistica Antverpiensia, New Series: Themes in Translation Studies, 18, 23-46.

spaces, as will be discussed in the following sections. Yet, in order to exemplify its concrete implications, I shall both mention some operational implementations of critical learning spaces and discuss them in relation to the mutual influence between MA and AVT ET programmes and MA and AVT practices.

\section{Normative frameworks in media accessibility}

As in other areas concerned with access issues, MA has been experiencing a series of radical changes at the ontological, epistemological, and methodological levels: a shift from particularist accounts to a universalist account of access, a shift from maker-centred to usercentred approaches, and a shift from reactive to proactive approaches. Whereas all of these bear relevant pedagogical and social implications, only the first of them will be concisely mentioned here. ${ }^{3}$ Various definitions of MA have been advanced over the years. Adopting the framework of AS, they can be clustered under two major families: a series of particularist accounts, on the one hand, and a universalist account, on the other (Greco, 2018). Particularist accounts can be further distinguished into first and second types. Accounts of the first particularist type define MA as a sub-domain of AVT and frame accessibility exclusively in relation to persons with (sensory) disabilities. The initial and most restrictive version confines MA solely to subtitling for the deaf and hard of hearing (SDH) and audio description (AD) (e.g., Orero, 2004); subsequent formulations include additional modalities, such as sign language interpreting or audio subtitling (e.g., Orero, 2012). Particularist accounts of the second type incorporate the aforementioned and then extend it to cover the other AVT modalities, such as dubbing and interlingual subtitling, making MA and AVT somehow overlap (e.g., DíazCintas, 2005; Orero \& Matamala, 2007).

On the contrary, the universalist account defines MA as concerning access to media and nonmedia objects, services and environments through media solutions, for any person who cannot or would not be able to, either partially or completely, access them in their original form (Greco, 2016b, 2018). The universalist account focuses on the processes involved in the interaction between users' specificities, the particular contexts in which they act or are placed, and the means to address such specificities in those contexts. This account avoids a multilayered conundrum faced by the particularist accounts, which $(a)$ restrict accessibility to some specific types of barrier and groups of people, and $(b)$ confine MA exclusively to translationand interpreting-based solutions. The universalist account positions MA within the instrumental view of accessibility, meaning that it does not limit accessibility to any predetermined group of people or barriers, and it provides a justification for the inclusion of nontranslation-based solutions in MA (Greco \& Jankowska, in press).

The three accounts are not axiologically neutral nor do they merely vary in what they consider to be part of MA. Refusing to acknowledge the importance of dealing with the different positions of MA, dismissing it as a mere matter of perspective, is highly controversial (Greco, 2019c). The critical lens of AS helps to reveal that they differ substantially because they are grounded in opposite value-laden and theory-laden views on accessibility and disability, and entail different ontological commitments on social reality (Calder, 2008). The first two accounts embody a particularist view based on a conception of accessibility that frames it in relation to disability. Disability, in turn, is seen by these accounts as a deviation from a norm, 
Greco, G. M. (2019). Towards a pedagogy of accessibility: The need for critical learning spaces in media accessibility education and training. Linguistica Antverpiensia, New Series: Themes in Translation Studies, 18, 23-46.

the very mechanism at the core of stigmatization (Goffman, 1963). The extension in the second account from sensory barriers to linguistic ones hides a mere interpretation of the latter as another category of the aforementioned degrading view of disability. Both accounts embed and facilitate the development of implicit biases, and therefore the perpetuation of discriminatory and oppressive practices. These two accounts, through implicit biases, link individuals to the stereotypes associated with their group(s). In doing so, they embody the medical model of disability, which assumes that disability is a personal problem due to the individuals' possessing an impairment that makes them deviate from a condition perceived as the norm. Within this model, the individuals need to be fixed through medical intervention in order to bring them as close as possible to normality. This model places the onus for addressing the problem exclusively on the individuals. Their social experience and the social dimension of the issue are completely ignored. Accordingly, within the two particularist accounts, MA services become instruments of medicalization that serve to compensate for a deviation and bring individuals back to a condition of perceived normality. It comes as no surprise, then, to read that

the goal [of $A D$ ] is to eliminate the barriers imposed by sensory impairment [emphasis added] when enjoying an audiovisual product and to place the person with a visual impairment as close as possible to a normal viewer [emphasis added], having the same information and also enjoying the film in the same way. (Sanz-Moreno, 2019)

This view of $A D$ is completely in line with the medical model: the cause of the barriers (disability) is the sensory impairment (individual problem) and the $A D$ aims at placing the person with a visual impairment as close as possible to a normal viewer (the $A D$ is an instrument of medicalization to bring the individual as close as possible to a condition perceived as the norm).

The universalist account, however, is radically different. As I discussed in Greco (2016b), it considers accessibility to be a matter concerning all human beings. It places disability within a human variation paradigm which is based on the idea that "difference is not an exception, not a monstrosity, but something that happens in the natural course of things" (Stiker, 1999/1997, p. 12). ${ }^{4}$ As such, the universalist account does not limit MA to any specific group. Rather, it focuses on the processes involved in the interaction between users' specific needs, abilities, and capabilities, the particular contexts within which they act or are placed, and the means to address those specific needs, value those specific abilities, and empower those specific capabilities in such contexts. This makes the universalist account more in line with the social model of disability, which views disability as a social construction. Disability is the product of the interaction between persons with impairments and a social environment designed and dominated by an ableist culture. The onus is shifted from the individual to society. According to this model, it is the social environment that needs to be fixed, not the individual.

Actually, once coupled with user-centred and proactive approaches (Greco, 2018) and with a poietic model of agency (Greco, 2013a, 2019b, 2019c; Greco \& Pedone, 2015), the universalist account even allows for addressing the limits of the social model of disability, which have been pointed out by many disability studies scholars (e.g., Shakespeare \& Watson, 2001; Thomas, 2007), and for overcoming them through what I have called an atimic or social model of accessibility (Greco, 2013a, 2017a, 2019c). In this model, disability is an instantiation of a 
Greco, G. M. (2019). Towards a pedagogy of accessibility: The need for critical learning spaces in media accessibility education and training. Linguistica Antverpiensia, New Series: Themes in Translation Studies, 18, 23-46.

general process of deterioration or negation of equal status to all human beings. According to the social model of accessibility, access problems concern all and the lack of access is not due to the specificities of each individual but to the incapacity of society to account fully for them. This model calls for an active participation of all agents involved, each one with a voice and a role in the co-construction of a solution. Accessibility then becomes the tool through which society should act poietically to create a social environment that is equitable and just for all (Greco, 2013a, 2019c).

\section{Accessibility and the need for critical learning spaces}

AS can be defined as the interdisciplinary field concerned with $(a)$ the critical investigation of access problems as well as access processes and phenomena, and $(b)$ the design, implementation and evaluation of accessibility-based and accessibility-oriented methodologies (Greco, 2017b, 2018, 2019c). In the specific context of this article, the term critical plays the central role.

Since its formal origins in the Frankfurt School, one of the major contributions of the school of thought called critical theory has been to highlight the emancipatory aim of the social sciences from social injustice (Habermas, 1988/1970; Horkheimer, 1972/1968). As social subjects, researchers and practitioners imbue their activities with values and biases. Beneath claims of objectivity and neutrality hide forms of subtle discrimination and oppression. Hence critical theorists' appeals for making explicit and scrutinizing the normative dimensions in any investigation and analysis of social phenomena. Building on this tradition, scholars working in different areas of the social sciences have been asserting the need to re-examine their fields through the lens of the aforementioned critical attitude in order to provide a new foundation for those fields. This explains the recent proliferation of new labels such as "critical legal studies", "critical gender studies", "critical disability studies", "critical management studies", and "critical regional studies". 5

However, such a line of thought does not apply to AS. Speaking of "critical accessibility studies" (or "critical access studies") would be redundant, a purely trivial exercise, for the critical attitude is an inherent trait of AS. Accessibility, the shifts it produces, and the principles they embody are instruments of theoretical and social design as well as of theoretical and social scrutiny. Within AS, critical denotes a Kantian stance that seeks to scrutinize and debunk theoretical, political, and social constructs, and, in doing so, to unveil controversial issues, biases, ambiguities, and conflicts. It expresses an attitude that considers both internal and external factors and forces, yet that also embodies a self-reflective practice. In sum, it demands that one be vigilant about the uses, misuses, and abuses of accessibility. The critical stance of AS should not be interpreted as an end in itself, but rather as a device for approaching and solving social problems poietically (Greco, 2019c).

Given its foundational character, the critical attitude should be a necessary element of any ET course that revolves around or involves accessibility. An ET programme that covers accessibility even partially but that does not provide students with the related critical knowledge and tools may, unintentionally, misuse accessibility or, depending on the case, even abuse it. It runs the risk of producing, encouraging or strengthening a discriminatory 
Greco, G. M. (2019). Towards a pedagogy of accessibility: The need for critical learning spaces in media accessibility education and training. Linguistica Antverpiensia, New Series: Themes in Translation Studies, 18, 23-46.

stance in students; that is, of training experts who, once in the job market, may create or reinforce a ghetto effect (Greco, 2016a, 2016b).

Consider an ET course in AVT that either explicitly or implicitly introduces students to accessibility by framing it from the most restrictive version of the first particularist account, that is, by limiting the concept of accessibility to persons with disabilities and confining MA to $A D$ and SDH. As I have discussed above, this account embodies the medical model of disability and its discriminatory traits. Such a course would then be training future experts who may, either consciously or unconsciously, generate or strengthen forms of discrimination through their work, precisely because they were educated in such a biased system. For example, they may design an access service in such a way that, despite their intention to conceive a tool that fosters social inclusion, may end up bolstering stigmatization.

The above risk is more than hypothetical. As I mention in the next section, the influence of the particularist accounts of $\mathrm{MA}$, and therefore of discriminatory normative assumptions such as the medical model, can be identified in many existing ET programmes in AVT and MA, including the initial drafts of two courses currently under development. Professional practices and education influence one another in a never-ending circle. Yet, in the case of AVT and MA, we know where the chicken came from, because practices were around for a very long time prior to their institutionalization in the education system. Therefore, the extent to which current mainstream practices are based on or are at least influenced by biased views, such as particularist accounts and the medical model of disability, seems to be a legitimate question. But it is a question tackled by only a few scholars thus far, and then only in relation to some specific modality, but never at the more general level of AVT and MA practices.

Udo and Fels (2010a, 2010b) analyse some limits of AD and SDH practices and guidelines. Limiting our attention to $A D$, they discuss how what they refer to as conventional $A D$ is "entrenched in the medical model of disability, needlessly limiting usership to a specific group with an intended outcome - the provision of equal access through $A D$ as an assistive technology" (Udo \& Fels, 2010b, p. 197). This is precisely a form of the first particularist account of MA, with $A D$ acting as a medicalization instrument for a specific group of people. In order to solve this problem and break free from the medical model, they suggest a change in both practices and education. They highlight the need to move towards a creation process of $A D$ in which the director is actively involved in the production of the $A D$ from the ex-ante stage through close collaboration with the audio describer and tests with users. In this process, $A D$ becomes one of the means through which the directors articulate their artistic vision and therefore a means for all, not just for a specific group. In recent years, their pioneering stance has been developed by Romero-Fresco $(2013,2019)$ into a detailed model for the integration of accessibility in film production, namely accessible filmmaking (AFM). According to Udo and Fels, their approach can be successfully mainstreamed precisely through a change in $A D$ education, "both in schools and on-the-job" (Udo \& Fels, 2010b, p. 196).

A similar dominance of the medical model, as expressed by the first particularist account of MA, has been discussed by DePoy and Gilson (2014) and Zdenek $(2011,2014,2015)$ in the case of SDH. Besides debating some issues related to current SDH practices, DePoy and Gilson show how even the label subtitles for the deaf and hard of hearing as well as the ways in which 
Greco, G. M. (2019). Towards a pedagogy of accessibility: The need for critical learning spaces in media accessibility education and training. Linguistica Antverpiensia, New Series: Themes in Translation Studies, 18, 23-46.

they are presented and offered in the media market act as instruments for disability branding and stigmatization. An even more explicit point is made by Zdenek in his analysis of SDH practices and guidelines. Through close examination of a plethora of cases, he argues how SDH practices tend to be dominated by a logocentric bias, which privileges speech over nonspeech at the expense of both the image and "the rhetorical work that sounds perform" (Zdenek, 2015, p. 117). The risk is a negative impact on equitable access not merely for deaf and hard of hearing users but for any user of SDH. He discusses how most practices and guidelines are imbued with an ableist attitude and "fail to account for captioning as a creative act of rhetorical invention" (Zdenek, 2015, p. 62). He calls for a new perspective that should be reoriented "away from an able-bodied, youth-oriented norm" (Zdenek, 2015, p. 14) and that should "inform our understanding of sound with an accessibility-infused sensitivity to the broader questions about sound, writing, and rhetoric" (Zdenek, 2011). As in Udo and Fels' case, the way to change practices is through a change in current models of education, which deny "our students a learning experience that's central to the composing practices we value, one that encourages them to think through the complexities of mode shifting and draw upon their powers of description in the process" (Zdenek, 2015, p. 291).

Finally, the influence of biased normative frameworks on MA practices is clearly evident in what I have called the maker-user gap and the maker-expert-user gap (Greco, 2013b, 2018), problems typically faced by particularist accounts of MA. In maker-centred and expert-centred approaches, as in the medical model, the maker and the expert conceive the user as a passive receiver with neither a voice nor a role in the process. However, this is not an issue encountered by the universalist account. On the one hand, it naturally calls for user-centred and proactive approaches. On the other hand, it is strictly linked to a poietic model of agency as a way to bridge those gaps (Greco, 2019c). Supported by extensive scholarly literature (e.g., Chaume, 2012; Mingant, 2010; Pedersen, 2011; Romero-Fresco, 2009; Sánchez-Mompeán, 2020), a widely accepted tenet in MA practices is that modalities should be designed so as to comply with Coleridge's mechanism of "the willing suspension of disbelief". However, Murray (1997) famously noted that "when we enter a fictional world, we do not merely 'suspend' a critical faculty; we also exercise a creative faculty. We do not suspend disbelief so much as we actively create belief" in order to "experience immersion" (p. 110). A similar point is made by Udo and Fels in their analysis of AD. ${ }^{6}$ They state that guidelines and practices tend to ignore "the entertainment experience as a whole" (2009, p. 179). They believe that AD should be designed as a series of stimuli to "elicit a reaction [in order to provide] AD users with an equivalent experience that is entertaining" (2010b, p. 191). From the wider perspective of AS, this means that, in order to bridge the gaps between makers, experts and users, we need to draw on "the poietic trait of accessibility" (Greco, 2019c, p. 24) and pay attention to the creative aspects involved in the processes of designing and experiencing. As suggested in Greco and Pedone (2015), accessibility design should follow the lead of health and safety planning, which has shifted from a prescriptive approach to a performance-based (or engineering) approach. While the former requires makers, and especially experts, to prosaically adhere to a set of technical rules, the latter requires that general objectives be reached through the creative design of solutions which flexibly respond to the specificities of the case at hand. In the context of MA practices, this would imply moving from prescriptive approaches, which mostly dominate the area, to a poietically-driven approach grounded on a new model of agency, where users are not passive recipients but co-creators of meaning, and 
Greco, G. M. (2019). Towards a pedagogy of accessibility: The need for critical learning spaces in media accessibility education and training. Linguistica Antverpiensia, New Series: Themes in Translation Studies, 18, 23-46.

where each agent - makers, experts, and users - plays an (inter)active role in the semantic construction of an experience. Once again, a preferential way to promote a poietic model of agency and a poietically-driven approach in MA practices is through its inclusion in ET programmes (Greco, 2019b).

Given the problems summarized in the previous paragraphs, courses based on particularist accounts root within students the very conceptual framework that justifies potentially discriminatory practices. By gradually shifting this analysis towards an operational level, it means that accessibility demands the inclusion within ET courses of critical learning spaces, where students can acquire the aforementioned critical attitude and apply it to the technical knowledge and skills they learn. Moreover, the idea of critical learning spaces or, more precisely, the critical lens of AS embedded in that idea, can also be used as a heuristic instrument in evaluating and designing ET courses. As we shall see through the analysis of two cases in the next section, the idea can help with identifying implicit biases and defining ways in which to amend them.

The idea of critical learning spaces should not be confused with ways of providing students with what are commonly called "transferable skills". Over the past few years, we have witnessed a massive surge in rhetoric that insists we should provide students with a set of transversal skills and competences, the list of which is in a state of continuous flux. Acquiring skills such as problem-solving, decision-making, leadership, and resilience will help students in their future tasks - so the liturgy goes - regardless of their specific job, the context, and the problem at hand. The idea of critical learning spaces does not refer to the technical skills and competences of a specific profile either - for example, in the case of an ET course on AD, the skills and competences related to how to write an AD. Until now, the vast majority of research on ET related to MA has been devoted to identifying and defining these sets of technical skills and competences as well as to the design of ET programmes able to provide them. Yet those sets do not have a permanently fixed number of elements. Their composition is subject to continuous revision because those types of skill will inevitably vary in response to advances in research, technological developments, and market demands. Paraphrasing what Pym (2003) says about the profile of the translator, precisely because the set of technical skills and competences is constantly subject to potential revision, it cannot be the basis upon which the distinctiveness of the profile of the (media) accessibility expert is grounded. Critical learning spaces deal with the skills and competences an accessibility expert should possess as accessibility expert. Continuing to tread in Pym's footsteps, one of the major challenges that future research should focus on is that of working towards a definition of a minimalist account of the (media) accessibility expert. That is, to work towards a definition that is able to grasp the essential features that identify a profile of a (media) accessibility expert and also to justify its distinctiveness from other profiles. The notion of critical learning spaces reveals a possible path along which future investigation could reach such a minimalist definition.

\section{Structure, function, and content of critical learning spaces}

Continuing the discussion at an operational level, the more an ET course focuses on accessibility, the more critical learning spaces should $(a)$ become the backbone which supports the other modules and topics, and $(b)$ permeate the other modules. This means that, in 
Greco, G. M. (2019). Towards a pedagogy of accessibility: The need for critical learning spaces in media accessibility education and training. Linguistica Antverpiensia, New Series: Themes in Translation Studies, 18, 23-46.

designing the curriculum of ET programmes, accessibility cannot be relegated to only a minor part of some module or merely be diluted across many modules. The centrality of accessibility in such courses entails two actions at the structural level of curricular design, each with a specific function. First, it requires a room of its own, that is, a module where students can be guided: to explore the ways in which accessibility transforms traditional conceptions of, for example, AVT; to realize how it helps to integrate the different topics and methods they will study; to understand the boundaries of traditional areas, then to move into new conceptual areas, and to deal with the troublesome aspects of this learning process (Perkins, 2006). All of this is necessary because it allows students to garner critical knowledge that will form the epistemological board upon which they will lay the various pieces to be acquired during the remainder of the course. Secondly, accessibility requires a room in the other modules, that is, spaces where students can apply the critical lens with which to unveil any normative assumptions hidden in the technical knowledge provided in these modules. Together, these critical learning spaces will also provide students with a set of critical tools they can (or should) use in their future practices.

Consider an ET course focused exclusively on AFM (Romero-Fresco, 2019). In an abstract sense, one could think of an ET course in AFM as being made up of three core groups of modules: a first group comprises modules on AVT, a second group modules on filmmaking, and a third modules on AFM. In such a threefold structure, accessibility would either be assigned as a topic in one of the groups, most likely the third one, or diluted among them. Yet, this raises some controversial issues. Given the central role played by accessibility in AFM and the potential ability of this approach to embody the three shifts in the contexts of filmmaking, AFM is not merely a form of AVT nor is it a form of filmmaking. Its nature is that of being applied accessibility studies (Greco, 2018; Romero-Fresco, 2018). The general scheme of an ET course in AFM made up only by those three groups would therefore be incomplete. The qualifying term in accessible filmmaking is accessibility, for it demarcates AFM both from other forms of filmmaking and from the variety of implementations of AVT in filmmaking. A fourth group is therefore necessary: one made up of (one or more) modules that focus explicitly and exclusively on accessibility.

The reason such a fourth group is necessary lies precisely in the role of accessibility as the defining core of AFM. Within AFM, accessibility acts like what scholars in the field of education call a threshold concept: "a conceptual gateway to the "ways of thinking and practising'" (Beaty, 2006, p. xi), which is "akin to a portal, opening up a new and previously inaccessible way of thinking about something" (Meyer \& Land, 2003, p. 412). In the context of AFM, accessibility is the lens through which students interpret AVT and filmmaking; it is the framework within which AFM practices are enclosed and distinguished from other forms of AVT and filmmaking; and it is the gateway that opens students to new ways of thinking about and doing AVT and filmmaking. Ultimately, accessibility acts as the very justification for the distinctiveness of AFM. Moving to the general level of ET programmes in MA, having a module focused entirely on accessibility provides students with a space for critical learning, where they deal with difficulties and secure the tools for addressing them. It is where they acquire the lens, build the framework, and start their journey to cross the gateway. It is the backbone upon which all the other modules are placed. 
Greco, G. M. (2019). Towards a pedagogy of accessibility: The need for critical learning spaces in media accessibility education and training. Linguistica Antverpiensia, New Series: Themes in Translation Studies, 18, 23-46.

However, simply adding a module focused on accessibility, while necessary, is not sufficient. Specific critical learning spaces should be included in the other modules in order to help guide students steadily and coherently out to the other end of the gateway. Suppose that in the initial module accessibility were introduced, and MA framed, within a universalistic account. A critical learning space in the module on AD would then help students to better position the knowledge acquired in this module in relation to the universalist account. It would also help to unmask potentially implicit discriminatory traits in the contents of this module - for example, contents that frame AD exclusively in relation to persons with visual disabilities or as an instrument for normalization in accordance with the medical model of disability - and prevent epistemic conflicts in the learning process.

But acknowledging the relevance of accessibility and acting accordingly by devising critical learning spaces, both as an introductory module and within the other modules, is still not sufficient. The way in which accessibility and other concepts such as disability are presented is also crucial. The selection and exposition of the contents of the various modules is influenced by implicit and explicit normative assumptions. They affect even the very sequential order in which these concepts are introduced.

Briefly discussing two actual cases will show how the critical lens of AS as presented thus far can facilitate the process of analysis and (re)design of curricula. It can help to identify and amend implicit biases in the planning of curricula, and also to recognize and prevent potential pedagogical risks in their future implementation. In recent years, we have witnessed the birth of projects led by AVT scholars that are specifically aimed at developing training courses dealing with accessibility - Easy Access for Social Inclusion Training (EASIT) ${ }^{7}$ and Interlingual Live Subtitling for Access (ILSA), ${ }^{8}$ for instance. The GALMA research group at the University of Vigo participates in both projects: in the former it is responsible for the definition of the skills cards; in the latter it serves as project coordinator. Each project revolves around identifying the skills and competences of one or more vocational profiles and then designing related training curricula: EASIT focuses on the experts in easy-to-understand subtitles, easy-tounderstand audio description, and easy-to-understand audiovisual journalism; ILSA on the interlingual respeaker. Both projects place accessibility as their social horizon, as explicitly indicated by their very titles. In these projects, a central activity is the delineation of a skills card for each profile. Skills cards are organized into modules and the modules are divided into units. For each unit, one or more learning outcomes (LOs) are defined.

The skills cards produced by the two projects are noteworthy cases because they are created as blueprints that anyone can use to build a course, meaning that a flaw in the blueprint may lead to structural problems in the actual building. A look at the initial drafts and the revised versions of the skills cards produced in these projects will illustrate some of the potential risks that were uncovered and then fixed through the explicit adoption and implementation of the perspective suggested in this article (full disclosure: as a member of GALMA, I was involved in the revision of the skills cards for both projects).

The final report of ILSA's Intellectual Output 4, titled 104: Mapping the New ILSA Course, includes a proposal for a new course structure, and states that "in line with the project name (Intralingual [sic] live subtitling ${ }^{9}$ for Access), a foundational component dedicated to media 
Greco, G. M. (2019). Towards a pedagogy of accessibility: The need for critical learning spaces in media accessibility education and training. Linguistica Antverpiensia, New Series: Themes in Translation Studies, 18, 23-46.

and live events accessibility (Module 1a, 1ECTS) has been added and is considered the very first foundational module" (Romero-Fresco et al., 2019, p. 23). It then specifies that "the reason is that offering access to media and live events through interlingual live subtitling is only one facet of accessibility, something students have to be aware of". While the foundational relevance of accessibility is acknowledged and the specific critical learning space(s) is included, an analysis of the initial structure and contents of this module revealed some problems. The first module is titled "Media and live events accessibility" and is organized into five units, in the following order: "Disability", "Accessibility and inclusion", "Live events accessibility", "Media accessibility", and "Users and services". The three LOs of the unit entitled "Disability" focus on the notion of disability and its historical evolution, different disability models and their language, and basic types and degrees of disability. The LOs of the second unit, "Accessibility and inclusion", focus on the notion of accessibility and inclusion, and legal aspects of accessibility at live events. This structure means that the very first content students are introduced to when starting the course is disability. Actually, it is the only content they learn before moving on to accessibility. As discussed in the previous sections, this poses the risk that such content design may bias students towards framing accessibility, once it is introduced in the second unit, as pertaining only to persons with disabilities. Moreover, one of the LOs of the unit "Media accessibility" concerns the particularist accounts and the universalist account of MA. Having first introduced students to disability may lead them to introject particularist accounts of MA, especially the first one. In the revised version of the skills card, the "Disability" unit was renamed "Human diversity" and a new LO that focused on the human variation paradigm was added at the very beginning in order to frame disability, and later, accessibility within this paradigm.

The last unit, "Users and services", of the first module provided further opportunities for improvement. Initially, the first LO of this unit read, "The student is able to enumerate the different target audiences that might ask for access support ( $A D, S D H$, sign language, etc.)"; that is, by referring to "different target audiences", the text seemed to endorse a universalist view. However, when it referred to access services, it explicitly mentioned only AD, SDH and sign language. Someone who would use the skills card to create an actual course may be influenced by this formulation. This is reinforced by the initial version of the second LO of this unit: "The student is able to enumerate the different types of access support according to the type of disability (sensory, physical, mental/intellectual and social)".

The remaining 12 learning outcomes of this unit focused exclusively on $A D$, subtitling, surtitling, SDH, and audio subtitling. Once paired with the sole reference to disability in the previous LOs, all of this highlighted how the initial design implicitly leaned towards the first particularist account. Actually, this also highlighted a further source of conflict, because of the inclusion of modalities such as subtitling, which are considered as being related to accessibility in the second particularist and the universalist accounts of MA, but not in the first particularist account. In the new draft of the skills card, any mention of specific modalities was removed from the first LO. The second LO was then changed to read, "The student is able to enumerate the different types of access support according to the types of users' needs, including types of disability (sensory, physical, mental/intellectual and social)", so as to frame disability in the general context of users' needs. Finally, a new LO was added so as to include at least an overview of further MA services and modalities. 
Greco, G. M. (2019). Towards a pedagogy of accessibility: The need for critical learning spaces in media accessibility education and training. Linguistica Antverpiensia, New Series: Themes in Translation Studies, 18, 23-46.

In the initial internal draft of all three skills cards produced by EASIT, the first module - entitled "Media Accessibility" - comprised four units in the following order: "What is universal design?"; "What is accessibility?"; "What is media accessibility?" and "Media accessibility services". This version included some valuable characteristics, such as having a specific unit for accessibility. However, it also presented a number of problems. First, it introduced accessibility after universal design. Since universal design is an instrument for addressing accessibility, the latter should naturally be introduced before the former, not vice versa. Secondly, the unit "What is universal design?" included only two LOs: one related to the definition and history of universal design and the other to user needs. As I discussed in Greco (2018), a specific component of many accessibility-oriented methodologies and processes, including universal design, is the promotion of proactive, user-centred, and participatory approaches. These approaches possess distinctive epistemological traits which are fundamental to the success of both the design process and the social implications of its results.

Over the past decade, scholars have been warning about how an uncritical adherence to and use of universal design principles may overlook its epistemic features and hinder proactive, user-centred, and participatory approaches (Imrie, 2012; Pullin, 2009; Vavik \& Gheerawo, 2009). Consequently, they should be addressed as a distinct topic, not subsumed under the general notion of universal design. All of these problems were successfully resolved during the second internal revision of the skills cards, which were later made available publicly for feedback. The outcomes of the amended versions comprised the following: first, in the new skills cards, the unit on accessibility now precedes the one on universal design; secondly, the unit on universal design now includes a third LO that focuses specifically on proactive, usercentred and participatory approaches; and, finally, a new unit titled "Human diversity" was added at the very beginning of the first module.

As these examples demonstrate, the issues discussed so far should not be treated as mere hypothetical risks. They are real problems faced by current ET programmes. In Greco (2019a) I discuss the results of an investigation that focused on the students of the Master of Arts in Audiovisual Translation at the Autonomous University of Barcelona. In the 2018-2019 edition, the initial part of the very first module of the programme was designed as a critical learning space. Special attention was devoted to the introduction of the universalist account and the related normative assumptions were made explicit - for example, by presenting disability from the human variation paradigm. Despite this, around four months later, only one student demonstrated having embraced the universalist account. The remaining 21 students had opted for one of the particularist accounts and displayed the use of discriminatory language. In line with the second particularist account and its interpretation of linguistic barriers according to a degrading view of disability, one student even generalized that the work of translators is "in fact helping the disabled." A reason for this bias may be found in the overall design of the course, which is in line with a very restrictive version of the first particularist account. Speaking of career opportunities, its website states that students might find work in "the fields of audiovisual translation, such as dubbing, subtitling, voice over, multimedia translation and videogame translation, as well as media accessibility, that is, audio description and subtitling for the deaf [emphasis added]" (Universitat Autònoma de Barcelona, 2019). ${ }^{10}$ This is then reflected in the curriculum, with a module entitled "Audio Description and Subtitling for the Deaf and Hard of Hearing." 
Greco, G. M. (2019). Towards a pedagogy of accessibility: The need for critical learning spaces in media accessibility education and training. Linguistica Antverpiensia, New Series: Themes in Translation Studies, 18, 23-46.

Perhaps because it is the oldest, the first particularist account has been wielding its influence for longer. Traces can be found in other leading academic programmes. Just consider the University of Cádiz's Master in Audiovisual Translation, which has a module titled "Audio Description Techniques for the Blind", and the University of Roehampton's Master of Arts in Audiovisual Translation, with an even more explicitly entitled module: "Media Access: Audiodescription [sic], Subtitling for the Deaf and Respeaking." Such a strong influence ultimately raises the question whether radical curriculum reform is in order to avert subtle forms of discrimination, like what Bolt (2012) calls the critical avoidance of disability in university education. This reform is indeed both necessary and possible. It is necessary if we want to avoid the risk of having practices and ET programmes that may, even implicitly, strengthen discriminatory frameworks. And it is possible, as proposed in these pages, through the use of the critical apparatus of AS for reformulating MA and AVT practices through their ET programmes.

\section{A note on two possible objections}

Before moving on to some concluding thoughts on the wider implications of a pedagogy of accessibility as well as its specific relevance to AVT and MA, let me briefly recap the general operational lines of the theoretical proposal I have advocated so far and then respond to two possible objections to its implementation.

As discussed in the previous pages, adopting the perspective of AS in ET programmes entails four joint actions. The first two actions deal with the structure and function of critical learning spaces. The third concerns the contents of the different modules, including the contents of critical learning spaces. The fourth relates to the very design of an ET programme. More specifically:

- The first action concerns the devising of an initial module through which students are provided with the critical tools useful to building the epistemological board on which they will place the knowledge they will acquire in the other modules and to self-reflect on their own practices. Although grossly oversimplified, we could refer to this module as the module on accessibility as long as it is clear that the goal of the module, and therefore of its content, is to provide students with the necessary critical apparatus, not merely to mention accessibility.

- The second action concerns the creation of specific critical learning spaces in the other modules - for example, in the form of one or more units in each module. These should help students to frame the specific content of a module - for example, on audio description - and the knowledge acquired in that module within the broader social dimensions of accessibility. These spaces of critical learning can also serve to identify, analyse, and, if necessary, redress specific biases and discriminatory practices that may have slipped back in during the course of an ET programme.

- The third action entails paying careful attention to the way in which the contents of each module are presented, for even the very order in which topics are introduced may hide and/or foster implicit biases. Consider the ILSA case analysed in the 
Greco, G. M. (2019). Towards a pedagogy of accessibility: The need for critical learning spaces in media accessibility education and training. Linguistica Antverpiensia, New Series: Themes in Translation Studies, 18, 23-46.

previous section: starting the foundational module with a unit on disability followed by one on accessibility is a clear example of the enduring influence of the first particularist account. A carefully planned initial unit on human diversity, however, could help redress the problem. For example, disability and accessibility could be framed within a human variation paradigm and a social model of accessibility, provided that the contents of the other two units are then also changed accordingly.

- The fourth action is related to a general principle that should guide the design and implementation of any ET programme that is either mainly or partially concerned with accessibility. This principle requires that the very design of an ET programme and the presentation of fundamental concepts such as accessibility and disability are executed from and framed using the critical apparatus of AS: adopting the human variation paradigm, the social model of accessibility, and the universalist account of access; highlighting the value of user-centred, proactive, and participatory approaches; promoting a poietic model of agency for makers, experts, and users; and so forth.

Some may object to the scheme above, especially the first three actions, claiming that they may have a negative impact on the contents of an ET programme. For example, some may say that, "[given some specific duration of an ET programme], if a group of modules on accessibility is added, this would inevitably mean that other skills cannot be developed" (Vercauteren, personal communication). ${ }^{11}$ The problem is ill-posed, however, as it is grounded on manifoldly fallacious argumentation. Actually, the line of thought behind this first objection is more than hypothetical. Let us recall the final report of ILSA's Intellectual Output 4. While the document argues in favour of an initial module on accessibility and refers to it as "the very first foundational module" of the ILSA curriculum (Romero-Fresco et al., 2019, p. 23), it also states "beware: this should be a light module (it should not take away practice hours)" (Romero-Fresco et al., 2019, p. 19). The objection taps into a distinction between the technical knowledge considered to be crucial to practice - for example, how to subtitle - and what I have termed critical knowledge, and it frames them as conflicting or even mutually exclusive. As I have said, the line of thought behind this objection is fallacious.

At a very general level, it is a version of the well-known theory vs practice dichotomy in education. Seeing that the deceitful aspects of this general dichotomy have been extensively debunked by many, I will not delve into them. ${ }^{12}$ In this context, it suffices to say that relegating critical knowledge to the purely theoretical realm with no practical relevance is controversial for many of the reasons cited by scholars in their analysis of that dichotomy. At another level, even if one considers the critical skills to be important for practice, that objection would imply that they are less important than other practical skills - for example, how to do subtitling. It would be like saying that physics and mathematics are secondary skills for civil engineers compared to their knowledge of how to use design software proficiently. Yet physics and mathematics skills are both very much related to as well as fundamental to their own practice. It is thanks to them that they can be sure that the public infrastructure they will design using the software will be safe and solid. Similarly, critical knowledge is very much practical for accessibility experts. For example, it will provide them with the tools that will help to avoid repeating the medical model of disability in their own practices. 
Greco, G. M. (2019). Towards a pedagogy of accessibility: The need for critical learning spaces in media accessibility education and training. Linguistica Antverpiensia, New Series: Themes in Translation Studies, 18, 23-46.

The time constraint expressed by such an objection is questionable too. Consider two generic ET programmes on the same vocational profile, one with a duration of 100 hours and another with a duration of 500 hours. The number of topics and the level of detail will vary considerably. Some topics that in the latter course will be discussed in depth will receive only a mere mention in the former course, or will even be ignored. Other topics will be unavoidable because they constitute the foundation upon which the profile and its skills are grounded. Merely reasoning in terms of length and practice would lead to the same ambiguity found in the ILSA report: in the curriculum developed by a project that explicitly uses accessibility as the justification for the profile and profession of the interlingual respeaker - as expressed even by the very name of the project - the skills on accessibility are important as long as they do not interfere with others that de facto are considered more important. However, the selection of the content should not be approached as a matter of limiting the time devoted to critical knowledge so as not to reduce the time devoted to the development of other skills. Instead, it should be a matter of calibrating the content of all modules, considering the aim, context and types of student, so that the fundamental tools can be provided in the amount of time available.

A second possible objection to my proposal may be related to the fourth action, that is, the design of ET programmes from and using the critical lens of AS. Some may claim that this defies the objectivity and neutrality of education programmes. Going back to critical theorists, however, objectivity and neutrality are mere illusions used to conceal normative views. As famously argued by Freire (1972/1968), the design of an education curriculum is always a political act. Even mathematics education, commonly perceived as an objective and neutral topic, is deeply intertwined with cultural, political, and social issues (Frankenstein, 1983). Scholars have shown, at length, how education programmes in mathematics are dominated by power structures: they reflect, justify, and preserve the socio-political status quo. ${ }^{13}$

The three shifts I have introduced in Greco (2018) form a model that is both descriptive and prescriptive. The model describes a series of trends that have been taking place (though not yet fully completed) in the areas interested in or by accessibility, including AVT and MA, and it prescribes the directions in which these areas should be further developed. The prescriptions on future directions are not limited to research, but heavily encompass education and practice. We need to rethink and redesign MA practices and education, which would entail moving away from those current structures that are based upon, reiterate and strengthen discriminatory assumptions such as the medical model of disability.

A final word on both objections. As already mentioned in the previous pages, the actions above should not be considered "extras" to tack on to the content of current curricula but rather as part of an overall strategy for curricular (re)design. Treating accessibility as an addon to current ET programmes means adopting a reactive approach in the context of education, which is likely to result in the same problems arising from reactive approaches in design. For example, cases in which the topic of disability is treated by merely adding some classes, a unit, or a module to current university education curricula have been well analysed and their limitations described in depth (e.g., see Penketh \& Waite, 2015). 
Greco, G. M. (2019). Towards a pedagogy of accessibility: The need for critical learning spaces in media accessibility education and training. Linguistica Antverpiensia, New Series: Themes in Translation Studies, 18, 23-46.

\section{Final thoughts: Towards a pedagogy of accessibility}

Let us now circle back to the initial questions of what, how and why we (should) teach. Accessibility has become a pervasive concept in our society, taking on a key role in a number of vastly different fields and disciplines. Accessibility is not just about a series of services, techniques, and technologies; nor is it merely a list of guidelines, procedures, and requirements. While all valuable, the related skills and competences are mostly connected to and affected by external forces such as the market and technological innovations. All of these skills can be effective and fruitful only if planted in solid and fertile ground, ground formed by the most fundamental competences an accessibility expert should have.

Reflecting on Otherness as a threshold concept in cultural studies, Cousin (2006) remarks on "the importance of creating spaces for students to personally engage with Otherness to avoid the risks of forms of mimicry which can be concealed in curriculum designs that exclude such engagement" (p. 145). One of the elements at the centre of accessibility is precisely the Other: our relationship with the Other, how we value the Other, and our actions towards the Other. This requires the creation of specific spaces in which students can both engage with knowledge that is transformative and acquire and practise the critical tools of AS. For example, engaging with the notion that accessibility concerns all human beings and not only some groups. Ultimately, AS provides a framework and a toolbox for social analysis and social design.

Education and training programmes must include these spaces, because they are where students are enabled to develop a modus cogendi which might become a forma mentis and then translate into a modus operandi. If they are not provided with the theoretical apparatus for being able to identify, analyse and modify discriminatory stances, or if they are but only partially, we run the risk of producing generations of experts with a biased forma mentis. These experts may, either consciously or unconsciously, overlook, reinforce or even create contexts of possible discrimination and oppression - for example, by designing products or policies based on the assumption that accessibility exclusively concerns persons with disabilities.

In his famous book, Invention: The Care and Feeding of Ideas, Wiener (1993) notes that

our schools must teach something more than conformity, and must demand something more than well-rounded nonentities. Whether the courses of the high school be in modern languages or classics or mathematics, they must recover a part of the bite and weight [emphasis added] they once had. Short of this, our civilization will drift into a Byzantine mediocrity, and our science will be governed by officials or employees, not by men. (p. 36)

Designing courses that include critical learning spaces means paying attention to the distinctive bite and weight of accessibility. Therefore, I believe there is the need for a wider discussion on a new model for accessibility education and training, which could then support and be coupled with a new model for accessibility practices. A model of training and practicing that is diversity-based, user-led, proactive-oriented, poietically-driven, and quality-centred. A model in which users are not implicitly or explicitly reduced to labels and categorised into stereotypes that frame them in terms of lacking what some dominant discriminatory paradigm 
Greco, G. M. (2019). Towards a pedagogy of accessibility: The need for critical learning spaces in media accessibility education and training. Linguistica Antverpiensia, New Series: Themes in Translation Studies, 18, 23-46.

establishes as the norm. A model that acknowledges their specificities and values them as part of human variation. A model where students and practitioners do not base their decisions on their own assumptions of users' specific needs, abilities, and capabilities. A model where users' knowledge is essential for understanding access issues and designing artefacts, and that promotes the involvement of users in the production processes because they are bearers of unique experiences. A model that prepares students to deal with the complex mechanisms of agency distribution in the design and implementation of accessible services and artefacts. A model that provides them with the skills necessary to manage accessibility as an integral part of the creative process, and to fruitfully interact with the poietic agency of the different actors involved, from the designers to the users. A model where access is understood as a requirement for all human beings, necessary for them to fulfil their full humanity. A model where accessibility cannot be reduced to the mere provision of access services for some groups following ways that may reiterate their discrimination. A model that goes beyond the mere focus on quantity of service and places at its centre the issue of quality of experience, because access is functional to the very possibility for each human to fully enjoy life. Within such a model, access becomes a vital instrument for human dignity.

We teach to prepare students for the future. The students we are training today will become the researchers of tomorrow, the professionals of tomorrow, and the policy-makers of tomorrow. The theoretical apparatus we provide them with today will influence their choices about which research paths to pursue and how, which services to provide, and how to design them. Perhaps most importantly, the apparatus will also affect the normative framework that influences the future direction of our society, because accessibility experts have been increasingly involved in policy-making bodies. Just think about the work of MA experts in standardization organizations (Matamala \& Orero, 2018) and the influence they may have in the processes that could lead to policies and standards on media accessibility quality.

Until now, the research and debate on accessibility education and training have focused mainly on practical skills, whereas the core competences of being an accessibility expert have largely been ignored. The unique bite and weight accessibility has on society demands that we train experts able to craft solutions while being fully aware of their social implications. Experts that are able to harness the poietic traits of accessibility. To quote Wiener's (1993) paraphrasing of Plato, "the artisans must become philosophers" (p. 8). Of all the areas from which AS has arisen, AVT and MA are most likely the domains in which training and education have been a central concern for the longest time and in the most extensive way. By complementing this lively debate with a discussion on the need for and the value of changes to current MA education systems and current MA practices towards an AS-grounded model, MA and AVT will help us to educate students and prepare professionals who will be both artisans and philosophers.

\section{Acknowledgments}

Previous drafts of this article were presented at: Disability and Disciplines 2019 - The International Conference on Educational, Cultural, and Disability Studies (Liverpool Hope University, 3-4 July 2019); Intermedia 2019 (University of Warsaw, 19-20 September 2019); PluriTAV. International Conference on Multilingualism, Translation and Language Teaching 
Greco, G. M. (2019). Towards a pedagogy of accessibility: The need for critical learning spaces in media accessibility education and training. Linguistica Antverpiensia, New Series: Themes in Translation Studies, 18, 23-46.

(University of València, 24-25 October 2019). I am grateful to the participants at those meetings for their feedback, to Anna Jankowska for her comments on an early draft and also to the two anonymous referees. My debt to Josh Branson, Kate Dangerfield, Iwona Mazur, Davide Ruggieri and Gert Vercauteren is even greater, because their sharp and detailed comments challenged me in ways I am not sure I have been able to meet exhaustively. Teressa Canosa skilfully copyedited the final version. Any remaining mistakes are mine.

The research presented in this article has received funding from the European Union's Horizon 2020 research and innovation programme under the Marie Sklodowska-Curie grant agreement No 752659 (project UMAQ); it has also been conducted within the frameworks of the EU-funded projects ILSA-Interlingual Live Subtitling for Access (2017-1-ES01-KA203037948) and EASIT-Easy Access for Social Inclusion Training (2018-1-ES01-KA203-050275). The author is a member of the TransMedia Catalonia research group, funded by the Catalan government under the SGR funding scheme (2017SGR113), and the GALMA research group, funded by the Galician government under the scheme Proxecto de Excelencia 2017.

\section{References}

Beaty, L. (2006). Foreword. In J. H. F. Meyer \& R. Land (Eds.), Overcoming barriers to student understanding: Threshold concepts and troublesome knowledge (pp. xi-xiii). Abingdon: Routledge.

Bolt, D. (2012). Social encounters, cultural representation and critical avoidance. In N. Watson, A. Roulstone, \& C. Thomas (Eds.), Routledge handbook of disability studies (pp. 287-297). New York, NY: Routledge.

Brownlee, K., \& Cureton, A. S. (Eds.). (2009). Disability and disadvantage. Oxford: Oxford University Press. doi:10.1093/acprof:osobl/9780199234509.001.0001

Calder, G. (2008). Ethics and social ontology. Analyse \& Kritik: Journal of Philosophy and Social Theory, 30(2), 427-443. doi:10.1515/auk-2008-0205

Chaume, F. (2012). Audiovisual translation: Dubbing. Manchester: St Jerome.

Clements, M. A. K., Bishop, A. J., Keitel, C., Kilpatrick, J., \& Leung, F. K. S. (Eds.). (2013). Third international handbook of mathematics education. New York, NY: Springer. doi:10.1007/978-14614-4684-2

Cousin, G. (2006). Threshold concepts, troublesome knowledge and emotional capital: An exploration into learning about others. In J. H. F. Meyer \& R. Land (Eds.), Overcoming barriers to student understanding: Threshold concepts and troublesome knowledge (pp. 134-147). Abingdon: Routledge.

DePoy, E., \& Gilson, S. F. (2014). Branding and designing disability: Reconceptualising disability studies. London: Routledge. doi:10.4324/9780203093542

Díaz-Cintas, J. (2008). Introduction: The didactics of audiovisual translation. In J. Díaz-Cintas (Ed.), The didactics of audiovisual translation (pp. 1-18). Amsterdam: John Benjamins. doi:10.1075/btl.77.03dia

Díaz-Cintas, J. (2005). Audiovisual translation today: A question of accessibility for all. Translating Today: The practical magazine for professionals around the world, 4, 3-5.

European Commission. (2015). ECTS users' guide 2015. Luxembourg: Publications Office of the European Union. doi:10.2766/87192

Frankenstein, M. (1983). Critical mathematics education: An application of Paulo Freire's epistemology. Journal of Education, 165(4), 315-339. doi:10.1177/002205748316500403

Freire, P. (1972). Pedagogy of the oppressed (M. Ramos, Trans.). (Original work published 1968). New York, NY: Herder and Herder. 
Greco, G. M. (2019). Towards a pedagogy of accessibility: The need for critical learning spaces in media accessibility education and training. Linguistica Antverpiensia, New Series: Themes in Translation Studies, 18, 23-46.

Goffman, E. (1963). Stigma: Notes on the management of spoiled identity. Englewood Cliffs, NJ: Prentice-Hall.

Greco, G. M. (2013a, June). The normative dimension of cultural accessibility. Paper presented at the First Italian Workshop on Cultural Accessibility, Lecce, Italy.

Greco, G. M. (2013b, September). Come e perché organizzare un evento culturale accessibile: Dalla teoria alla pratica. Paper presented at ArtLab13, Lecce, Italy.

Greco, G. M. (2016a, February). Accessibility, human rights, and the ghetto effect. Paper presented at Wounded Places: On the Integrity of the Body, Beirut, Lebanon.

Greco, G. M. (2016b). On accessibility as a human right, with an application to media accessibility. In A. Matamala \& P. Orero (Eds.), Researching audio description: New approaches (pp. 11-33). London: Palgrave Macmillan. doi:10.1057/978-1-137-56917-2_2

Greco, G. M. (2017a). L'accessibilità culturale come strumento per i diritti umani di tutti. In G. Cetorelli \& M. R. Guido (Eds.), Il patrimonio culturale per tutti: Fruibilità, riconoscibilità, accessibilità (pp. 94-105). Roma: Direzione Generale Musei, Ministero dei Beni e delle Attività Culturali e del Turismo.

Greco, G. M. (2017b, June). The need for accessibility studies. Paper presented at The Future of Media Accessibility: Issues and Visions, Lecce, Italy.

Greco, G. M. (2018). The nature of accessibility studies. Journal of Audiovisual Translation, 1(1), 205232. Retrieved from http://www.jatjournal.org/index.php/jat/article/view/51/10

Greco, G. M. (2019a). Accessibility and epistemological problems in audiovisual translation education. Manuscript in preparation.

Greco, G. M. (2019b). The question of accessibility. In E. Perego \& C. Taylor (Eds.), The Routledge handbook of audio description. London: Routledge. Manuscript in preparation.

Greco, G. M. (2019c). Accessibility studies: Abuses, misuses and the method of poietic design. In C. Stephanidis (Ed.), Lecture Notes in Computer Science: Vol. 11786. HCl International 2019: Late Breaking Papers (pp. 15-27). Cham: Springer. doi:10.1007/978-3-030-30033-3_2.

Greco, G. M., \& Jankowska, A. (in press). Media accessibility within and beyond audiovisual translation. In Ł. Bogucki \& M. Deckert (Eds.), The Palgrave handbook of audiovisual translation and media accessibility. Cham: Palgrave Macmillan.

Greco, G. M., \& Pedone, L. (2015). Accessibilità e sicurezza dei luoghi di spettacolo: Note su criteri impositivi, criteri prescrittivi e buone prassi. Lecce: AGM.

Habermas, J. (1988). On the logic of the social sciences (S. H. Nicholsen \& J. A. Stark, Trans.). (Original work published 1970). Cambridge, MA: MIT Press.

Horkheimer, M. (1972). Critical theory: Selected essays (M. J. O'Connel, Trans.). (Original work published 1968). New York, NY: Seabury Press.

Imrie, R. (2012). Universalism, universal design and equitable access to the built environment. Disability \& Rehabilitation, 34(10), 873-882. doi:10.3109/09638288.2011.624250

Jablonka, E., Wagner, D., \& Walshaw, M. (2013). Theories for studying social, political and cultural dimensions of mathematics education. In M. A. K. Clements, A. J. Bishop, C. Keitel, J. Kilpatrick, \& F. K. S. Leung (Eds.), Third international handbook of mathematics education (pp. 41-67). New York, NY: Springer. doi:10.1007/978-1-4614-4684-2_2

Koskinen, K. (2010). What matters to translation studies? On the role of public translation studies. In D. Gile, G. Hansen, \& N. K. Pokorn (Eds.), Why translation studies matters (pp. 15-26). Amsterdam: John Benjamins. doi:10.1075/btl.88.03kos

Laviosa, S. (2004). Corpus-based translation studies: Where does it come from? Where is it going? Language Matters: Studies in the Languages of Africa, 35(1), 6-27. doi:10.1080/ 10228190408566201

Matamala, A., \& Orero, P. (2018). Standardising accessibility: Transferring knowledge to society. Journal of Audiovisual Translation, 1(1), 139-154. Retrieved from http://www.jatjournal.org/ index.php/jat/article/view/49/8 
Greco, G. M. (2019). Towards a pedagogy of accessibility: The need for critical learning spaces in media accessibility education and training. Linguistica Antverpiensia, New Series: Themes in Translation Studies, 18, 23-46.

Meyer, J. H. F., \& Land, R. (2003). Threshold concepts and troublesome knowledge: Linkages to ways of thinking and practising within the disciplines. In C. Rust (Ed.), Improving student learning: Improving student learning theory and practice - Ten years on (pp. 412-424). Oxford: Oxford Centre for Staff and Learning Development.

Mingant, N. (2010). Tarantino's Inglourious Basterds: A blueprint for dubbing translators? Meta: Translators' Journal, 55(4), 712-731. doi:10.7202/045687ar

Murray, J. H. (1997). Hamlet on the holodeck: The future of narrative in cyberspace. New York: The Free Press.

Orero, P. (2004). Introduction: Audiovisual translation: A new dynamic umbrella. In P. Orero (Ed.), Topics in audiovisual translation (pp. VII-XIII). Amsterdam: John Benjamins. doi:10.1075/btl.56.01ore

Orero, P. (2012). Film reading for writing audio descriptions: A word is worth a thousand images? In E. Perego (Ed.), Emerging topics in translation: Audio description (pp. 13-28). Trieste: Edizioni Università di Trieste.

Orero, P., \& Matamala, A. (2007). Accessible opera: Overcoming linguistic and sensorial barriers. Perspectives: Studies in Translatology, 15(4), 262-277. doi:10.1080/13670050802326766

Pedersen, J. (2011). Subtitling norms for television: An exploration focussing on extralinguistic cultural references. Amsterdam: John Benjamins. doi:10.1075/btl.98

Penketh, C., \& Waite, L. (2015). Lessons in critical avoidance. In D. Bolt \& C. Penketh (Eds.), Disability, avoidance and the academy: Challenging resistance (pp. 68-78). London: Routledge. doi:10.4324/9781315717807-7

Perkins, D. (2006). Constructivism and troublesome knowledge. In J. H. F. Meyer \& R. Land (Eds.), Overcoming barriers to student understanding: Threshold concepts and troublesome knowledge (pp. 33-46). Abingdon: Routledge.

Pullin, G. (2009). Design meets disability. Cambridge, MA: MIT Press.

Pym, A. (1991). A definition of translational competence, applied to the teaching of translation. In M. Jovanovic (Ed.), Translation: A creative profession: 12th World Congress of FIT Proceedings (pp. 541-546). Belgrade: Prevodilac.

Pym, A. (2003). Redefining translation competence in an electronic age: In defence of a minimalist approach. Meta: Translators' Journal, 48(4), 481-497. doi:10.7202/008533ar

Robinson, D. (2017). Critical translation studies. Abingdon: Routledge. doi:10.4324/9781315387864

Romero-Fresco, P. (2009). Naturalness in the Spanish dubbing language: A case of not-so-close Friends. Meta: Translators' Journal, 54(1), 49-72. doi:10.7202/029793ar

Romero-Fresco, P. (2013). Accessible filmmaking: Joining the dots between audiovisual translation, accessibility and filmmaking. The Journal of Specialised Translation, 20, 201-223.

Romero-Fresco, P. (2018). In support of a wide notion of media accessibility: Access to content and access to creation. Journal of Audiovisual Translation, 1(1), 187-204. Retrieved from https://www.jatjournal.org/index.php/jat/article/view/53/12

Romero-Fresco, P. (2019). Accessible filmmaking: Integrating translation and accessibility into the filmmaking process. London: Routledge. doi:10.4324/9780429053771

Romero-Fresco, P., Robert, I., Pöchhacker, F., Dutka, Ł., Szcygielska ${ }^{14}$, M., \& Decuyper, M. (2019). 104 report: Mapping the new ILSA course. Retrieved from http://www.ilsaproject.eu/wpcontent/uploads/2019/07/1O4_Report.pdf.

Sánchez-Mompeán, S. (2020). The prosody of dubbed speech: Beyond the character's words. Cham: Palgrave Macmillan. doi:10.1007/978-3-030-35521-0

Sanders, J. T., \& McPeck, J. E. (1976). Theory into practice or vice versa? Comments on an educational antinomy. The Journal of Educational Thought, 10(3), 188-193.

Sanz-Moreno, R. (2019). How to deal with intertextuality in AD? Almodóvar's The Skin I Live In: A case study. inTRAlinea, 21. Retrieved from http://www.intralinea.org/archive/article/2348 
Greco, G. M. (2019). Towards a pedagogy of accessibility: The need for critical learning spaces in media accessibility education and training. Linguistica Antverpiensia, New Series: Themes in Translation Studies, 18, 23-46.

Scotch, R. K., \& Schriner, K. (1997). Disability as human variation: Implications for policy. The Annals of the American Academy of Political and Social Science, 549(1), 148-159. doi:10.1177/0002716297549001011

Shakespeare, T., \& Watson, N. (2001). The social model of disability: An outdated ideology? In S. Barnarrt \& B. M. Altman (Eds.), Exploring theories and expanding methodologies: Where are we and where do we need to go? (pp. 9-28). Bingley: Emerald. doi:10.1016/S1479-3547(01)80018$\mathrm{X}$

Stiker, H-J. (1999). A history of disability (W. Sayers, Trans.). (Original work published 1997). Ann Arbor, MI: University of Michigan Press. doi:10.3998/mpub.15952

Thomas, C. (2007). Sociologies of disability and illness: Contested ideas in disability studies and medical sociology. London: Palgrave Macmillan.

Trickett, E. J., Watts, R. J., \& Birman, D. (1994). Toward an overarching framework for diversity. In E. J. Trickett, R. J. Watts, \& D. Birman (Eds.), The Jossey-Bass social and behavioral science series: Human diversity: Perspectives on people in context (pp. 7-26). San Francisco, CA: Jossey-Bass.

Udo, J.-P., \& Fels, D. I. (2009). "Suit the action to the word, the word to the action": An unconventional approach to describing Shakespeare's Hamlet. Journal of Visual Impairment and Blindness, 103(3), 178-183. doi:10.1177/0145482X0910300307

Udo, J.-P., \& Fels, D. I. (2010a). The rogue poster-children of universal design: Closed captioning and audio description. Journal of Engineering Design, 21(2), 207-221. doi:10.1080/09544820903310691

Udo, J.-P., \& Fels, D. I. (2010b). Universal design on stage: Live audio description for theatrical performances. Perspectives: Studies in Translatology, 18(3), 189-203. doi:10.1080/0907676X.2010.485683

Universitat Autònoma de Barcelona. (2019). Máster Oficial - Traducción Audiovisual: Información general. Retrieved from https://www.uab.cat/web/estudiar/la-oferta-de-masteresoficiales/informacion-general/x-1096480309770.html?param1=1345695508608

avik, T., \& Gheerawo, R. (2009). The challenges in universal design. In T. Vavik (Ed.), Inclusive buildings, products \& services: Challenges in universal design (pp. 4-24). Trondheim: Tapir Academic Press.

Wiener, N. (1993). Invention: The care and feeding of ideas. Cambridge, MA: MIT Press.

Zdenek, S. (2011). Which sounds are significant? Towards a rhetoric of closed captioning. Disability Studies Quarterly, 31(3). doi:10.18061/dsq.v31i3.1667

Zdenek, S. (2014). More than mere transcription: Closed captioning as an artful practice. User Experience: The Magazine of the User Experience Professionals Association, 14(1). Retrieved from http://uxpamagazine.org/more-than-mere-transcription

Zdenek, S. (2015). Reading sounds: Closed-captioned media and popular culture. Chicago, IL: University of Chicago Press. doi:10.7208/chicago/9780226312811.001.0001 
Greco, G. M. (2019). Towards a pedagogy of accessibility: The need for critical learning spaces in media accessibility education and training. Linguistica Antverpiensia, New Series: Themes in Translation Studies, 18, 23-46.

1 The use of the term module should be intended as indicating the largest pieces that make up the mosaic of a specific programme. Consider a generic Master of Arts in Audiovisual Translation, which is organized into several modules, such as Theory of AVT, Dubbing and Voice Over, Methodology of AVT, and so on. The module Dubbing and Voice Over could be then organized into a sub-module on dubbing and one on voice over, and each sub-module could be further organized into units.

2 Currently, the only course that has MA in the title is the MOOC on Media Accessibility produced within the HBB4ALL project. The course is made up of four modules: Accessibility, Subtitling, Audio Description, and Sign Language. Analysed through the critical lens of AS, such a structure suggests that the course is designed from and framed within a particularist account of MA. See http://accessguide.tv/course.

3 For a more extensive discussion, I refer the reader to Greco (2018).

4 For an overview of the human variation paradigm, see also Brownlee \& Cureton (2009); Scotch \& Schriner (1997); Trickett, Watts, \& Birman (1994).

5 Over the years, a few scholars have used the label critical translation studies. Differently from other fields, the label has been mainly adopted to refer to an area within (e.g., Laviosa, 2004), a subfield of (e.g., Koskinen, 2010), or a methodological approach within (e.g., Robinson, 2017) Translation Studies rather than as a re-foundational perspective for the whole field.

6 In Udo \& Fels (2010a), they extend this line of thought to SDH.

7 http://pagines.uab.cat/easit/en.

8 http://www.ilsaproject.eu.

9 The terms "live" and "subtitling" are not capitalized in the original text.

10 The original text reads: "Ios campos de la traducción audiovisual, como el doblaje, la subtitulación, las voces superpuestas, la traducción multimedia y la traducción de videojuegos, así como la accesibilidad a los medios, es decir, el audio descripción y la subtitulación para sordos" (Universitat Autònoma de Barcelona, 2019).

11 I am grateful to Gert Vercauteren for having drawn my attention to this important point. The quoted text is extrapolated from one of his comments to the penultimate version of this article.

12 For a sharp and concise analysis of the fallacious aspects of this dichotomy, I refer the reader to Sanders \& McPeck (1976).

13 For an overview of both the issues and the literature on the cultural, social, and political dimensions in mathematics education, I refer the reader to many chapters in the first part of Clements, Bishop, Keitel, Kilpatrick, \& Leung (2013), especially that by Jablonka, Wagner, \& Walshaw (2013).

14 The published article includes this typographical error. The correct surname is Szczygielska. 